American Journal of Pharmaceutical Education 2018; 82 (1) Article 6275.

\title{
COMMENTARY
}

\section{Third-Party Onboarding Organizations as Gatekeepers for Student Placement Decisions}

\author{
Jennifer Danielson, PharmD, MBA, ${ }^{a}$ Courtney Kraus, PharmD, ${ }^{b}$ Curtis G. Jefferson, MS, ${ }^{a}$ \\ Anita J. Cleven, PharmD, ${ }^{b}$ Luke E. Rice, MEd, ${ }^{\mathrm{c}}$ Teresa A. O’Sullivan, PharmD ${ }^{\mathrm{a}}$ \\ ${ }^{\text {a }}$ University of Washington School of Pharmacy, Seattle, Washington \\ ${ }^{\mathrm{b}}$ Pacific University Oregon School of Pharmacy, Hillsboro, Oregon \\ ${ }^{\mathrm{c}}$ Washington State University, Spokane, Washington \\ Submitted January 12, 2017; accepted March 14, 2017; published February 2018.
}

\begin{abstract}
Health system human resource departments are putting new requirements, paperwork, and processes in place to meet new Joint Commission standards for treating students like employees who onboard at the beginning of employment. These processes have significantly increased the workload of experiential education offices and present an additional burden to students. In an attempt to streamline these processes, health systems are contracting with third-party tracking and placement organizations. Converting this process to an electronic one (such as what third-party organizations offer) could present advantages; however, there are many concerns about going through a third-party organization that could control placement decisions. This commentary describes these concerns and provides guidance to schools should they choose to work with one of these organizations.
\end{abstract}

Keywords: pharmacy education, experiential learning, organization and administration

In May 2011, The Joint Commission (TJC) adopted a new human resources (HR) standard for contracted and volunteer personnel. ${ }^{1}$ This standard and the accompanying interpretation state that students participating in clinical training activities must be treated the same as other paid personnel (eg, direct employees). ${ }^{2}$ As such, all health systems' HR departments must manage the orientation and onboarding process for students just like they would for all direct employees. Consequently, all health systems now require pharmacy students, as well as all other health professions learners, to comply with the same onboarding procedures as employees do before starting onto each clinical rotation. These new procedures represent additional steps for all students, schools, and health system HR departments never before needed.

This onboarding process includes verifying candidate qualifications (education and licensure), confirming the individual is unlikely to transmit infectious disease (immunizations and screening), performing criminal background checks, and providing an orientation. ${ }^{2-7} \mathrm{Per}$ interpretations of this TJC standard, ${ }^{8}$ health systems HR departments may contract through affiliation agreement

Corresponding Author: Jennifer Danielson, University of Washington School of Pharmacy, Box 357630, Office of Professional Pharmacy Education, South Campus Center, Suite 244, 1601 NE Columbia Road, Seattle, WA 98195. Tel: 206-543-1924. Fax: 206-221-2689. E-mail: jendan@uw.edu with schools to attest that these requirements have been met; however, audits of these records are required to be considered fully compliant. In addition, monthly searching of the US Department of Health and Human Services Office of Inspector General Excluded Provider List for each individual provider is a requirement for all health care sites funded by the Center for Medicare and Medicaid Services and many state-provided insurance programs. ${ }^{9}$ To stay compliant with these standards, most health system HR offices have begun requiring students to complete additional paperwork and orientation modules, and requiring schools to verify compliance with background checks, immunization status, and other details before allowing students on site.

The pharmacy department and preceptors who host students are frequently unaware or do not appreciate the extent of paperwork and training activities required by their health system's HR department. Since implementation of this TJC standard, experiential education offices have shouldered the growing burden of tracking these requirements for all students and reporting them for each placement in a health system. ${ }^{10}$ For example, the University of Washington hired an additional employee to perform this tracking, monitoring, and reporting which must happen anywhere from 30 to 60 days prior to each rotation for each student throughout the year. School staff continuously monitor and update student records to verify licensing, immunizations and screening tests, criminal 


\section{American Journal of Pharmaceutical Education 2018; 82 (1) Article 6275.}

background checks, and the specific certifications and/or trainings (eg, cardiopulmonary resuscitation, orientation to the Health Insurance Portability and Accountability Act [HIPAA], malpractice insurance, blood-borne pathogens prevention, and fraud, waste, and abuse). Staff members also locate and submit forms required by each individual health care system to the HR personnel prior to each individual student pharmacy practice experience. While some health systems trust that schools are tracking these requirements, most require schools to document the requirements on forms specific to the health care system and submit them each month. The duplication in tracking, certifying, and submitting forms is burdensome.

The state of Oregon has taken the approach of enacting legislation to ensure students' clinical placement onboarding is standardized across health professions and across clinical placement sites. As of July 1, 2014, all health professions program students completing clinical training in Oregon must have documentation of current immunizations, health screenings, basic training (CPR, BLS), background checks, and drug/substance abuse screening. In addition, all clinical placement sites in Oregon may not impose additional or more stringent administrative requirements unless specific exception rules are met. This layer of legislative oversight is intended to reduce inconsistencies in student onboarding, ensure patient, clinical staff, and student safety, and promote efficiency while reducing costs for students. ${ }^{11} \mathrm{Be}-$ cause health professions students in neighboring states may share clinical placement sites between those neighboring states, as is the case for health professions students in Oregon and Washington, this presents an additional tracking burden. On the surface, Oregon's approach through legislation seems an effective one, but unless there is standardization of onboarding administrative requirements across states, then it is one more item to track.

In some regions of the country, health systems are collaborating to streamline this onboarding process for health professions students. In Washington, a non-profit consortium of health systems and nursing education programs, Clinical Placements Northwest (CPNW), has created training programs accepted by member health care systems and offers an electronic tracking system that could potentially streamline reporting processes for both health systems and schools. For-profit compliance businesses, such as Complio and myClinicalExchange, operate in other regions of the country. Such third-party placement organizations should streamline onboarding for HR departments, but will only streamline the onboarding process for pharmacy schools if the process for the third-party placement organization replaces that of the HR department. If the HR department continues to require information submitted on their proprietorial forms, then the third-party organization training requirements will merely increase the onboarding burden, with no benefit to schools and students.

Another concern is that these third-party placement organizations have effectively become gatekeepers for student placements within a health care system. Working through such a third-party organization is required if a school wants to place a student within a health system that has contracted with the organization. These thirdparty organizations charge students a fee for this service. The school typically pays this fee and passes the cost along to students as a course fee. In Washington State, in addition to tracking compliance requirements, CPNW also manages all nursing student placement decisions within their health care system members. Consequently, nursing schools and their students have little or no choice in where and when students are placed, because CPNW controls and manages this process. This third-party organization has recently begun requiring all non-nursing health professions students to use their services for onboarding students. Pharmacy schools need to ensure that third-party organizations do not attempt to take over student placement decisions at the health systems served by those organizations.

We support streamlining the onboarding process for students at multiple health systems and envision that a common electronic system could provide the needed data storage, tracking, and reporting processes that our experiential education staff does. Working with a thirdparty organization may, in fact, be a cost-effective way to manage the process of verifying education status/requirements, licensure, health status (immunizations), and background checks that TJC requires. However, we do not support outsourcing important placement decisions to an external, non-pharmacy-related organization and paying a per-student fee to do so. Our relationships and affiliation agreements are with pharmacists and pharmacy departments for the advancement of pharmacy education and practice, not an external organization. Pharmacy schools must maintain the authority to make placement decisions based on established quality criteria for preceptors and practice sites to ensure students gain practice experiences consistent with curricular goals, stated learning objectives and required educational outcomes. ${ }^{12}$ Control over where and when students are placed is necessary in order for schools to meet accreditation standards (ie, provide students with required and elective experiences of appropriate breadth, depth, and timing, as well as opportunity to explore interests and achieve career goals). ${ }^{13,14}$ As the practice of pharmacy evolves to include provider status, schools need the ability to choose 


\section{American Journal of Pharmaceutical Education 2018; 82 (1) Article 6275.}

experiences for students that exemplify practice models in which they want their students to practice upon graduation. Optimally, schools work directly with pharmacy departments within health systems (not an external organization) to meet our common goals of producing practice-ready pharmacy graduates that health systems want to hire.

Another concern is the fees students must pay to use these systems for a task we already do in our experiential education offices. Going through a third-party organization adds additional steps to the onboarding process for students, while failing to reduce the amount of tracking that we do at the school. The value of this added cost seems empty and without benefit.

Since third-party onboarding organizations do not cover all health systems a school works with to place students, an inherent inequity is present. Some students pay the fee and some do not based on whether the health systems in which they are placed work with that organization. Does this set up an unfair system where some students must "pay to play?" Is it fair to ask a student to pay this additional cost for just one APPE as opposed to those who do multiple APPEs within a system that contracts with such an organization?

Several questions must be asked. Could such thirdparty placement organizations force schools to "join" (ie, pay) in order to place students in a particular system? In an effort to reduce workload, are health system HR departments seeking to outsource both onboarding/compliance processes and actual placement decisions to an external organization? Are the pharmacy departments with whom we place students aware of these extra steps students and schools complete? Would they want their HR department or an external organization deciding the number of students placed with their preceptors and when?

External, non-pharmacy organizations are not familiar with pharmacy educational standards. They are not equipped to assess preceptor engagement, provide evaluation and quality assurance, set and monitor student-to-preceptor ratios that are educationally sound (not financially driven), and provide preceptor development that advances practice. ${ }^{12}$ Third-party placement organizations are not equipped to deal with the repercussions of poorly considered student placements. Experiential education personnel know their students and preceptors and can guide students toward placements at sites where they can build desired skills or away from sites that may not be ideal for their skill level or working style.

Proliferation of third-party placement organizations and onboarding systems raises questions that have broad implication for all pharmacy schools across the country. We would hope that we work together in pharmacy education across institutions to get questions answered about these third-party placement organizations. While we are not opposed to finding more cost-effective ways to process HR requirements, we must draw the line at having to negotiate with (and pay) a third-party organization for placement decisions. Should your school encounter a similar organization, we hope that you will seek answers to these questions and pay particular attention to the language in affiliation agreements so that our educational mission remains intact.

\section{REFERENCES}

1. The Joint Commission. Human resource standards - applicability to contracted and volunteer personnel. https://www.jointcommission.org/ standards_information/jcfaqdetails.aspx?StandardsFAQId $=1325 \&$ print $=y$. Accessed January 5, 2017.

2. The Joint Commission. Standards FAQ details: Human resources, hospital and hospital clinics/hospitals: Primary source verification definition. Accessed January 5, 2017. https://www.jointcommission. org/standards_information/jcfaqdetails.aspx?StandardsFAQId= 1245\&StandardsFAQChapterId $=66 \&$ ProgramId $=0 \&$ ChapterId $=0 \&$ IsFeatured $=$ False $\&$ IsNew $=$ False $\&$ Keyword $=$.

3. The Joint Commission. Appendix E: comparison of human resources standards for HCSS certification and hospital accreditation (AXE), 2013. http://www.jointcommission.org/assets/1/6/ crosswalk_hospital_hr_standards_staffing_standards.pdf. Accessed January 5, 2017.

4. The Joint Commission. Standards FAQ details: infection prevention and control, hospital and hospital clinics/hospitals: health screening, licensed independent practitioner. https://www. jointcommission.org/standards_information/jcfaqdetails.aspx? StandardsFAQId $=1202 \&$ StandardsFAQChapterId $=69 \&$

ProgramId $=0 \&$ ChapterId $=0 \&$ IsFeatured $=$

False \&IsNew $=$ False \&Keyword $=$. Accessed January 5, 2017.

5. The Joint Commission. Standards FAQ details: human resources, hospital and hospital clinics: criminal background checks requirements. https://www.jointcommission.org/standards_information/ jcfaqdetails.aspx? StandardsFAQId=1321\&StandardsFAQChapterId= $66 \&$ ProgramId $=0 \&$ ChapterId $=0 \&$ IsFeatured $=$ False $\&$ IsNew $=$ False\&Keyword $=$. Accessed January 5, 2017.

6. Compliance department. Does Joint Commission require criminal background checks? Response and analysis. Certiphi Screening, Inc. https://www.certiphi.com/resource-center/background-screening/ joint-commission-criminal-background-checks/. Accessed January 5, 2017.

7. Occupational Safety and Health Administration. Safety and health management systems and Joint Commission standards. US Department of Labor. https://www.osha.gov/dsg/hospitals/documents/2.2_SHMSJCAHO_comparison_508.pdf. January 5, 2017.

8. Joint Commission. Human resource standards applicability to contracted and volunteer personnel. Standards FAQ details, 2011. https://www.calhospital.org/sites/main/files/file-attachments/ The_Joint_Commission_-_Standards_FAQ_Chapter.pdf. Accessed December 28, 2016.

9. Frequency of OIG screening. Certiphi Screening, Inc. https:// www.certiphi.com/resource-center/compliance-services/frequencyof-oig-screening/. Accessed January 5, 2017. 


\section{American Journal of Pharmaceutical Education 2018; 82 (1) Article 6275.}

10. Danielson J, Craddick K, Eccles D, Kwasnik A, O'Sullivan TA. A qualitative analysis of common concerns about challenges facing pharmacy experiential education programs. Am J Pharm Educ. 2015;79(1):Article 6.

11. Accreditation Council for Pharmacy Education. Standards 20 (Preceptors) and 22 (Practice Facilities). Accreditation standards and key elements for the professional program in pharmacy leading to the doctor of pharmacy degree. https://www.acpe-accredit.org/pdf/ Standards2016FINAL.pdf. Accessed February 3, 2015.

12. Accreditation Council for Pharmacy Education. Standard 13 (APPE Curriculum). Accreditation standards and key elements for the professional program in pharmacy leading to the doctor of pharmacy degree. Accessed February 3, 2015. https://www.acpe-accredit.org/ pdf/Standards2016FINAL.pdf.

13. Accreditation Council for Pharmacy Education. Guidance for the APPE Curriculum: Standard 13. Guidance for the accreditation standards and key elements for the professional program in pharmacy leading to the doctor of pharmacy degree. Accessed February 3, 2015. https://www.acpe-accredit.org/pdf/ GuidanceforStandards2016FINAL.pdf.

14. Or. Admin. Rule 409-030-0100-409-030-0250. Administrative requirements for health profession student clinical training. http:// arcweb.sos.state.or.us/pages/rules/oars_400/oar_409/409_030.html. Accessed January 6, 2017. 